\title{
Conversion of short-term potentiation to long-term potentiation in mouse CAl by coactivation of $\beta$-adrenergic and muscarinic receptors
}

\author{
Steven A. Connor, ${ }^{1}$ Sabyasachi Maity, ${ }^{2}$ Birbickram Roy, ${ }^{4}$ Declan W. Ali, ${ }^{1,4}$ \\ and Peter V. Nguyen ${ }^{1,2,3,5}$ \\ ${ }^{1}$ Centre for Neuroscience, ${ }^{2}$ Department of Physiology, ${ }^{3}$ Department of Psychiatry, University of Alberta School of Medicine, Edmonton, \\ Alberta, T6G 2H7, Canada; ${ }^{4}$ Department of Biological Sciences, University of Alberta, Edmonton, Alberta, T6C 2E9, Canada
}

\begin{abstract}
Encoding new information requires dynamic changes in synaptic strength. The brain can boost synaptic plasticity through the secretion of neuromodulatory substances, including acetylcholine and noradrenaline. Considerable effort has focused on elucidating how neuromodulatory substances alter synaptic properties. However, determination of the potential synergistic interactions between different neuromodulatory systems remains incomplete. Previous results indicate that coactivation of $\beta$ adrenergic and cholinergic receptors facilitated the conversion of STP to LTP through an extracellular signal-regulated kinase (ERK)-dependent mechanism. ERK signaling has been linked to synaptically localized translation regulation. Thus, we hypothesized that costimulation of noradrenergic and cholinergic receptors could initiate the transformation of STP to LTP through up-regulation of protein synthesis. Our results indicate that a protocol which yields STP $(5 \mathrm{~Hz}, 5 \mathrm{sec})$ when paired with coapplication of the $\beta$-adrenergic agonist, isoproterenol (ISO), and the cholinergic agonist, carbachol (CCh), induces translationdependent LTP in mouse CA1. This form of LTP requires both $\beta 1$-adrenergic and Ml muscarinic receptor activation, as blocking either receptor subtype prevented LTP induction. Blocking ERK, $\mathrm{mTOR}$, or translation reduced the expression of LTP induced with ISO + CCh. Taken together, our data demonstrate that coactivation of $\beta$-adrenergic and muscarinic receptors facilitates the conversion of STP to LTP through a mechanism requiring translation initiation.
\end{abstract}

Memory formation is believed to rely on an activity-dependent, enduring modification of synaptic strength known as long-term potentiation (LTP) (Bliss and Lomo 1973; Bliss and Collingridge 1993; Kandel 2001). LTP has been demonstrated in the hippocampus following events which induce behavioral changes indicative of learning and memory (Whitlock et al. 2006). The hippocampus plays a time-limited role in the establishment of new memories (Scoville and Milner 1957; Zola-Morgan et al. 1986; Neves et al. 2008), a process subject to modification through the release of neuromodulatory transmitters.

Cholinergic and noradrenergic neuromodulatory systems can enhance synaptic plasticity (Hu et al. 2007; Dringenberg et al. 2008; Fernández de Sevilla et al. 2008) and long-term memory formation (Cahill et al. 1994; Harley et al 2006; Kukolja et al. 2009). Conversely, blocking cholinergic or noradrenergic receptors impairs memory function (Wallenstein and Vago 2001; Kemp and Manahan-Vaughan 2008). Acetylcholine affects neuronal function through stimulation of nicotinic and muscarinic receptors, which can initiate bidirectional changes in synaptic strength (Leung et al. 2003; Scheiderer et al. 2008). Noradrenaline activates $\alpha$ - and $\beta$-adrenergic receptors which can, likewise, elicit opposing effects on cell excitability and synaptic plasticity (Gelinas et al. 2008; Lemon et al. 2009). Activation of either muscarinic (Shinoe et al. 2005; Li et al. 2007; Poulin et al. 2010) or $\beta$-adrenergic receptors (Thomas et al. 1996; Walling and Harley 2004; Gelinas and Nguyen 2005; Lemon et al. 2009) can enhance synaptic strength and memory formation.

\footnotetext{
${ }^{5}$ Corresponding author

E-mail peter.nguyen@ualberta.ca

Article is online at http://www.learnmem.org/cgi/doi/10.1101/lm.026898.112.
}

Although the individual contributions of $\beta$ - and muscarinic receptors to synaptic function have been investigated, the effects of simultaneous activation of these receptors have yet to be fully elucidated. Previous research has demonstrated that coactivation of $\alpha$-adrenergic and muscarinic receptors facilitates the induction of long-term depression (LTD) (Scheiderer et al. 2008). LTD induced by $\alpha$-adrenergic and M1 receptors is facilitated through a synergistic elevation of extracellular signal-regulated kinase (ERK) phosphorylation. A similar effect on ERK stimulation was observed when the $\beta$-adrenergic receptor agonist, isoproterenol (ISO), was paired with carbachol (CCh), a broad-spectrum muscarinic agonist (Watabe et al. 2000). However, pairing ISO with CCh lowered the threshold for LTP induction in contrast to the facilitative effects of LTD observed when $\alpha$-adrenergic and muscarinic receptors were costimulated. Given that ERK activation initiates translation (Banko et al. 2006; Gelinas et al. 2007), the results of the Watabe et al. (2000) study suggest that $\beta$ - and muscarinic receptor agonists could facilitate the induction of LTP through a protein synthesis-dependent mechanism. We sought to further characterize the downstream signaling cascades mediating the conversion of short-term potentiation (STP) to LTP observed following costimulation of $\beta$ - and muscarinic receptors in mouse CA1.

In line with previous data (Watabe et al. 2000), coactivation of $\beta$ - and muscarinic receptors lowered the threshold for the induction of LTP by brief low-frequency stimulation (LFS; $5 \mathrm{~Hz}, 5$ sec). We identified the $\beta 1$ - and M1 receptor subtypes as the primary receptors responsible for enhancing LTP, as application of pirenzepine (M1 muscarinic receptor antagonist; $250 \mathrm{nM}$ ) or ( \pm )-2-Hydroxy-5-[2-[[2-hydroxy-3-[4-[1-methyl-4-(trifluoromethyl)-1H-imidazol-2-yl]phenoxy]propyl] amino]ethoxy]-benzamide methanesulfonate salt (CGP) ( $\beta 1$-AR antagonist; $1 \mu \mathrm{M}$ ) 
prevented the induction of LTP. We also observed that inhibition of ERK and mTOR (mammalian target of rapamycin) similarly prevented the maintenance of LTP induced by ISO $(200 \mathrm{nM})$ paired with CCh $(200 \mathrm{nM})$. To probe the role of translation, we applied the protein synthesis inhibitors emetine $(20 \mu \mathrm{M})$ and cycloheximide $(80 \mu \mathrm{M})$ overlapping with receptor stimulation. These inhibitors blocked the maintenance of LTP, indicating a requirement for translation. These data suggest that coactivation of $\beta$ - and muscarinic receptors recruits translation to enhance synaptic strength. As cholinergic and noradrenergic systems are associated with memory formation and neurodegenerative diseases (Caccamo et al 2006; Yu et al. 2011), these data suggest that determining how different neuromodulatory systems interact to regulate synaptic plasticity should increase our understanding of how these processes may be altered in neurodegenerative disorders.

\section{Results}

As both cholinergic and noradrenergic receptors are capable of augmenting synaptic strength (Gelinas and Nguyen 2005; Dringenberg et al. 2008) and prior evidence suggested that interactions between these neuromodulatory receptors may influence synaptic plasticity (Watabe et al. 2000; Scheiderer et al. 2008), we sought to identify mechanisms mediating the potential synergistic effects of $\beta$-and muscarinic receptor activation. To determine if LFS alone is sufficient for inducing LTP, we applied 5-Hz, 5-sec stimulation in the absence of receptor agonists. LFS alone induced a transient potentiation of extracellular field excitatory postsynaptic potentials (fEPSPs) which returned to baseline in $<45$ min (mean fEPSPs were $102 \pm 3 \%$ of baseline 60 min after stimulation; $n=8$ ) (Fig. 1A). Similarly, application of either ISO or CCh paired with LFS failed to induce LTP. Application of CCh paired with LFS induced transient potentiation which returned to baseline: mean fEPSPs were $100 \pm 4 \%$ of baseline $60 \mathrm{~min}$ after stimulation $(n=$ 10) (represented in histogram, Fig. 1D). Pairing ISO with LFS also resulted in decremental LTP; mean fEPSPs were reduced to $98 \pm 4 \%$ of baseline 60 min post-LFS ( $n=12$ ) (Fig. 1D). To test if coapplication of ISO and CCh is sufficient for inducing synaptic plasticity, we coapplied both drugs while monitoring baseline fEPSPs. A 15-min application of ISO and CCh was insufficient for augmenting synaptic responses. When measured $60 \mathrm{~min}$ after termination of drug application, mean fEPSPs were $98 \pm 6 \%(n=10)$ of baseline (Fig. 1D). Coapplication of ISO and CCh followed 10 min later with $5-\mathrm{Hz}$, 5 -sec stimulation resulted in enhanced LTP (mean fEPSPs were potentiated to $137 \pm 9 \%$ of baseline $60 \mathrm{~min}$ post-LFS; $n=10$ ) (Fig. $1 \mathrm{~B}, \mathrm{D})$. Next, to control for upward baseline drift in response to application of ISO $+\mathrm{CCh}$, the stimulation intensity was reduced $3 \mathrm{~min}$ prior to tetanization with $5 \mathrm{~Hz}$. The stimulation intensity was maintained at this new set point for the remainder of the experiments. LTP was still observed with this protocol (fEPSPs were $123 \pm$ $7 \%, n=5$ ) (Fig. 1C). An ANOVA comparing all groups revealed a significant effect of treatment $\left(\mathrm{F}_{(5,49)}=7.97 ; P<0.05\right)$. A TukeyKramer post-hoc test revealed that persistent LTP was observed when ISO and CCh were coapplied and paired with low-frequency stimulation $(5 \mathrm{~Hz}, 5 \mathrm{sec})$. Comparisons of fEPSP magnitudes $60 \mathrm{~min}$ post-stimulation showed that $\mathrm{ISO}+\mathrm{CCh}+5 \mathrm{~Hz}$ induced LTP which was significantly enhanced relative to all other groups $(P<$ 0.05) (Fig. 1D), except the ISO + CCh +5 Hz with reduced stimulation intensity prior to $5 \mathrm{Hzstimulation}$, which was not significantly different $(P>0.05)$.

\section{$\beta 1$ - but not $\beta 2$-ARs are required for LTP induced by ISO + CCh}

To determine if $\beta$-adrenergic receptors are required for the induction of LTP by ISO and CCh, we applied a general $\beta$-adrenergic
A
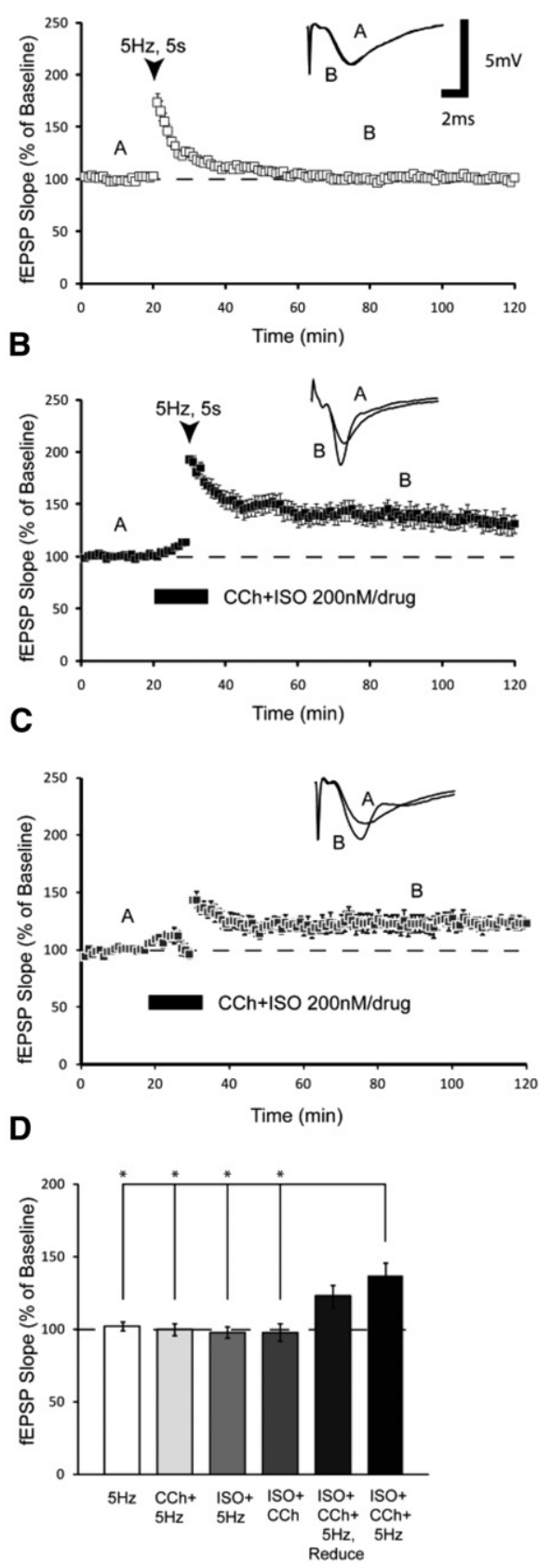

E

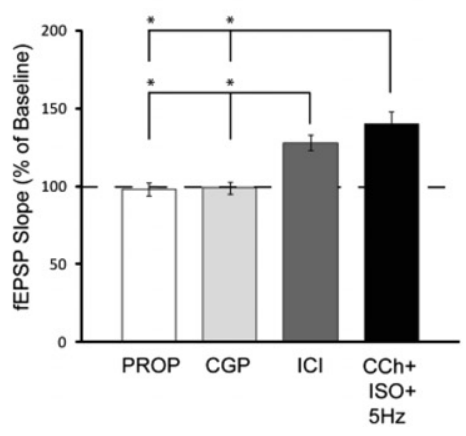

Figure 1. (Legend on next page) 
receptor antagonist, propranolol (PROP; $50 \mu \mathrm{M}$ ) overlapping with $\mathrm{ISO}+\mathrm{CCh}+5 \mathrm{~Hz}$ stimulation. Application of PROP blocked the expression of long-lasting LTP; mean fEPSPs were $98 \pm 4 \%$ of baseline $(n=9) 60 \mathrm{~min}$ after tetanization (represented in histogram, Fig. 1E). To further characterize the $\beta$-AR subtype responsible for the ISO-induced effects on LTP, we used the $\beta 1$-specific antagonist CGP $(1 \mu \mathrm{M})$. Application of CGP during ISO + CCh application blocked the induction of LTP (mean fEPSPs were $99 \pm 4 \%$ of baseline $60 \mathrm{~min}$ post-stimulation, $n=9$ ) (Fig. 1E). In contrast, inhibition of $\beta 2$-ARs with the specific $\beta-2$ antagonist, $( \pm)-1-[2,3-$ (Dihydro-7-methyl-1H-inden-4-yl)oxy]-3-[(1-methylethyl)amino]-2-butanol hydrochloride (ICI; $1 \mu \mathrm{M}$ ), failed to inhibit LTP (Fig. $1 \mathrm{E})$. Sixty minutes after stimulation, mean fEPSPs were still potentiated to $128 \pm 5 \%(n=8)$ (Fig. 1E) of baseline. An ANOVA comparing groups treated with antagonists demonstrated a significant effect of drug treatment on LTP $\left(\mathrm{F}_{(3,30)}=15.44 ; P<0.01\right)$ (Fig. 1E). Subsequent Tukey-Kramer post-hoc analysis revealed that both propranolol and CGP significantly reduced the persistence of LTP relative to slices treated with ISO, CCh, and 5- Hz stimulation in the absence of antagonists (Fig. 1E). Conversely, inhibition of $\beta 2$ yielded LTP which was not significantly different from antagonist-free controls $(P>0.05)$.

\section{Inhibition of the $\mathrm{Ml}$ muscarinic receptor subtype blocks ISO + CCh LTP}

As an initial step in the characterization of the muscarinic component of ISO + CCh LTP, we applied the broad-spectrum muscarinic receptor antagonist atropine $(50 \mu \mathrm{M})$. Application of atropine overlapping with stimulation of $\beta$ - and muscarinic receptors prevented the induction of LTP. In the presence of atropine, fEPSPs returned to baseline $(97 \pm 5 \%)$ within 60 min of LFS $(n=8)$ (Fig. 2A). Next, we applied the selective M1 muscarinic receptor antagonist pirenzepine dihydrochloride (PIR; $250 \mathrm{nM}$ ). Similar to slices treated with atropine, LTP was not observed in slices exposed to PIR; (mean fEPSPs were $103 \pm 4 \%$ of baseline 60 min after tetanization; $n=12$ ) (Fig. 2B). To determine if M3 receptors are required for ISO + CCh-LTP, we used the M3 antagonist, 4-diphenylacetoxy$\mathrm{N}$-methylpiperidine methiodide (4-DAMP; $1 \mu \mathrm{M}$ ). Blocking M3 receptors did not prevent the expression of LTP. Mean fEPSPs were potentiated to $131 \pm 5 \%(n=8)$ (summarized in histogram, Fig. 2E) of baseline when assessed $60 \mathrm{~min}$ after 5 - Hz stimulation. Next, we tested if M2/M4 receptors are engaged during ISO- and CCh-induced LTP. Induction of LTP in the presence of the M2/

Figure 1. Coactivation of $\beta$ - and muscarinic receptors facilitates the induction of LTP by low-frequency stimulation. (A) Tetanization of Schaffer collateral fibers with $5-\mathrm{Hz}$ stimulation for $5 \mathrm{sec}$ induces transient $(<45 \mathrm{~min})$ LTP $(n=8)$. (B) When LFS is applied following a 10-min application of ISO + CCh, STP is converted to LTP which is significantly enhanced relative to all other treatments $(n=10)$. (C) Reducing stimulation intensity prior to application of $5 \mathrm{~Hz}$ to control for increased baseline responses during drug application does not block the expression of LTP. (D) Summary histogram comparing fEPSP slopes obtained $60 \mathrm{~min}$ after LFS. Data for $5 \mathrm{~Hz}$ paired with either ISO or CCh are summarized in $D$. $\left({ }^{*}\right)$ Significant differences between treatment groups. $(E)$ Histogram representing data characterizing $\beta$-adrenergic receptor component of ISO + CCh LTP. $\beta$-ARs are required for enhancement of LTP induced by ISO paired with CCh. Similar to the broad-spectrum $\beta$-AR antagonist, propranolol (PROP) (data not shown, summarized in $E$ ), specific inhibition of $\beta 1$ by CGP completely abolished the enhancing effects of ISO paired with CCh on LTP $(n=9)$. Blocking $\beta 2$-ARs with the specific antagonist ICI $(n=$ 8) yielded LTP that was similar in magnitude to control slices not exposed to inhibitor $(n=8)$. Both summary histograms compare fEPSP slopes obtained $60 \mathrm{~min}$ after LFS. Sample traces were taken $10 \mathrm{~min}$ after commencement of baseline recordings and $60 \mathrm{~min}$ after stimulation. Results in $D$ and $E$ represent means \pm SEM. $\left(^{*}\right) P<0.05$.
A
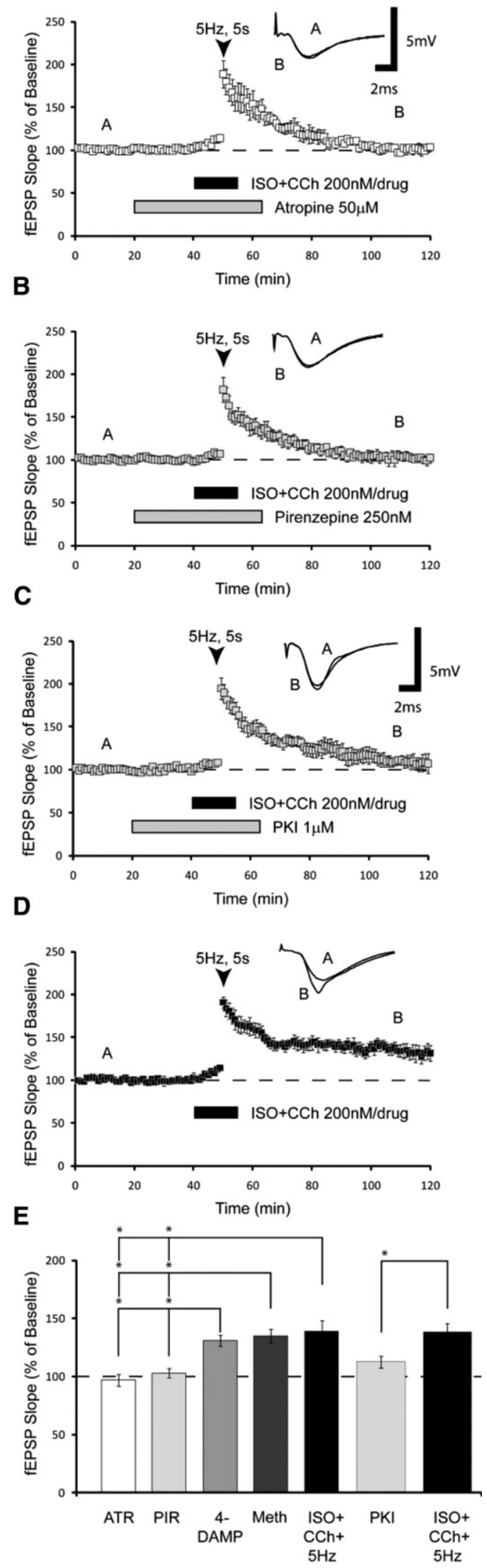

Figure 2. (Legend on next page) 
M4 antagonist, methoctramine $(250 \mathrm{nM})$, yielded mean fEPSPs that were potentiated to $135 \pm 6 \%$ of baseline $60 \mathrm{~min}$ after stimulation $(n=6)$ (Fig. 2E). An ANOVA was conducted to compare all slices exposed to inhibitors and control slices treated with ISO + $\mathrm{CCh}+5 \mathrm{~Hz}$. A significant effect of treatment was observed $\left(\mathrm{F}_{(4,37)}=11.27 ; P<0.01\right)$ (Fig. 2E). Tukey-Kramer post-hoc tests revealed that blocking muscarinic receptors nonselectively with atropine prevented the expression of LTP $(P<0.01)$. Similarly, inhibition of M1, but not M2/M4 or M3, prevented the expression of LTP $(P<0.01)$. Slices treated with 4-DAMP (M3) or methoctramine $(\mathrm{M} 2 / \mathrm{M} 4)$ were indistinguishable from $\mathrm{ISO}+\mathrm{CCh}+$ $5 \mathrm{~Hz}$ controls $(P>0.05)$ (Fig. $2 \mathrm{E})$.

\section{Inhibition of PKA prevents the expression of LTP following coactivation of $\beta$ - and muscarinic receptors}

Both muscarinic and $\beta$-adrenergic receptors can modulate synaptic function through downstream activation of kinases, including PKA (Winder et al. 1999; Fernández de Sevilla and Buño 2010). Thus, we sought to determine if PKA is required for LTP induced by ISO and CCh. Application of a membrane permeant inhibitor of PKA, PKA Inhibitor 14-22 Amide (PKI; $1 \mu \mathrm{M}$ ), overlapping with ISO + CCh prevented the expression of LTP (mean fEPSPs were $110 \pm 5 \%$ of baseline $60 \mathrm{~min}$ after stimulation; $n=11$ ) (Fig. 2C). A subsequent comparison between slices treated with PKI and control slices in which PKA activation was intact $(134 \pm 7 \% ; n=8)$ (Fig. 2D) showed a significant difference between groups $(P<0.01)$ (Fig. 2E).

\section{ERK and $m$ TOR are required for LTP induced by $\mathrm{ISO}+\mathrm{CCh}$}

Both $\beta$-adrenergic (Gelinas and Nguyen 2005) and muscarinic receptors (Feig and Lipton 1993) can promote translationdependent LTP. Stimulation of $\beta$-adrenergic receptors increases translation through signaling cascades coupled to mTOR and ERK (Gelinas et al. 2007). To test the hypothesis that coactivation of $\beta$ - and muscarinic receptors can engage downstream mTOR activity to facilitate LTP, we used the mTOR inhibitor, rapamycin (RAP; $1 \mu \mathrm{M}$ ). Slices treated with RAP during simultaneous activation of $\beta$ - and muscarinic receptors demonstrated decremental LTP (mean fEPSPs had returned to $97 \pm 6 \%$ of baseline 90 min after 5-Hz stimulation; $n=6$ ) (Fig. $3 \mathrm{~A}$ ). It has been shown that pairing ISO with CCh induces LTP mediated through ERK (Watabe et al. 2000). To determine if ERK activation was required, we applied the MEK inhibitor, 1,4-diamino-2,3-dicyano-1,4-bis[2-aminophenylthio] butadiene (U0126; $20 \mu \mathrm{M}$ ), during the coactivation of

Figure 2. Muscarinic receptors are required for LTP induced by coactivation of $\beta$ - and muscarinic receptors. ( $A$ ) Treating slices with the broadspectrum muscarinic receptor antagonist atropine resulted in decremental LTP which returned to baseline in $<45 \mathrm{~min}(n=8)$. (B) The M1 muscarinic receptor antagonist pirenzepine similarly inhibited the induction of LTP when applied overlapping with ISO and CCh application $(n=12)$. Conversely, application of the M3 muscarinic receptor antagonist failed to prevent LTP as potentiation was still observed 60 min poststimulation $(n=8$; summarized in $E)$. Inhibition of M2/M4 receptors with methoctramine yielded LTP which was similar to nonmethoctramine controls $(n=6 ; E)$. Control slices treated with ISO $+\mathrm{CCh}+5 \mathrm{~Hz}$ generated LTP which was significantly enhanced relative to slices exposed to atropine and pirenzepine $(n=8 ; E)$. (C) PKA is required for facilitated LTP observed during costimulation of $\beta$ - and muscarinic receptors. Pairing of the membrane permeant PKA inhibitor, PKI, with costimulation of $\beta$ and muscarinic receptors prevented the bolstering of LTP $(n=11)$ relative to $(D)$ slices not treated with PKI $(n=8)$. (E) Summary histogram comparing fEPSP slopes obtained 60 min after LFS. (*) Significant differences between treatment groups $(P<0.05)$. Sample traces were taken $10 \mathrm{~min}$ after commencement of baseline recordings and $60 \mathrm{~min}$ after LFS. Results in $E$ represent means \pm SEM. $\beta$-and muscarinic receptors. Consistent with previous findings, inhibition of MEK prevented the expression of LTP (90 min after LFS in the presence of U0126, mean fEPSPs had diminished to $98 \pm 7 \%$ of baseline; $n=8$ ) (Fig. 3B). As both ERK and mTOR recruit translation regulation (Banko et al. 2006; Gelinas et al. 2007), we next explored whether inhibition of protein synthesis impairs LTP induced by coactivation of $\beta$ - and muscarinic receptors.

\section{ISO and CCh engage translation to facilitate LTP}

A requirement of protein synthesis has been observed in both long-term synaptic plasticity and long-term memory (Abraham and Williams 2008). Thus, we tested the hypothesis that protein synthesis is necessary for expression of LTP induced by ISO paired with CCh. We found that application of a translational repressor, emetine (EME; $20 \mu \mathrm{M}$ ), during ISO + CCh treatment generated LTP which reverted to baseline levels (mean fEPSPs were $101 \pm$ $4 \% ; n=8$ ) (Fig. 3C) when measured 90 min after LFS. To control for off-target effects of emetine, we conducted a second series of experiments using another protein synthesis inhibitor, cycloheximide (CHX; $80 \mu \mathrm{M})$. Treatment with $\mathrm{CHX}$ resulted in decaying LTP that was $102 \pm 4 \%(n=7)$ of baseline 90 min post-stimulation (Fig. 3D). A control synaptic pathway was monitored during cycloheximide experiments which did not significantly deviate from predrug baseline responses, suggesting slice health was not compromised (Fig. 3D). Subsequent comparisons (ANOVA) between slices treated with RAP, U0126, EME, CHX, or no inhibitor demonstrated a significant effect of treatment on the magnitude of LTP at 90 min post-stimulation $\left(\mathrm{F}_{(4,33)}=6.64 ; P<0.05\right)$ (Fig. $3 \mathrm{~F})$. Inhibition of mTOR, ERK, or translation resulted in LTP that was substantially reduced relative to ISO $+\mathrm{CCh}$ controls (Fig. 3E,F). No significant differences between EME-, cycloheximide-, RAP-, or U0126-treated groups were observed $(P>0.05)$.

\section{Discussion}

It is widely accepted that synaptic activity suprathreshold for engaging translation is critical for establishing enduring synaptic modifications (Stanton and Sarvey 1984; Frey et al. 1988; Nguyen et al. 1994). The ability of synapses to undergo activity-dependent plasticity can be bolstered through activation of neuromodulatory receptors which initiate translation regulation (Frey et al. 1988, 1991; Watabe et al. 2000; Gelinas and Nguyen 2005; Scheiderer et al. 2008). Through combined application of $\beta$-adrenergic and muscarinic receptor agonists, LTP induced by low-frequency stimulation $(5 \mathrm{~Hz}, 5 \mathrm{sec})$ was significantly enhanced relative to slices treated with stimulation alone, or stimulation paired with either agonist alone. The functional importance of this form of LTP is demonstrated by a requirement for translation which links this form of LTP to evidence implicating protein synthesis-dependent LTP in long-term memory formation (Abel et al. 1997; Straube et al. 2003; Walling and Harley 2004; Herrera-Morales et al. 2007).

A critically important question is how distinct neuromodulatory systems in the brain cooperate to influence synaptic plasticity, memory formation, and behavioral adaptations. Neuromodulators, including noradrenaline and acetylcholine, can modify a diverse range of neural functions including synaptic plasticity (Watabe et al. 2000; Gelinas and Nguyen 2005; Scheiderer et al. 2008). Much research has focused on the effects of these neurotransmitters in isolation; however, few studies have addressed how combinations of neuromodulators affect regulation of synaptic plasticity. Previous research has established that coactivation of $\beta$ - and muscarinic receptors reduces the threshold for induction of LTP (Watabe et al. 2000) and that noradrenergic and muscarinic signals interact to augment the ability of hippocampal synapses to undergo long-term depression 
A
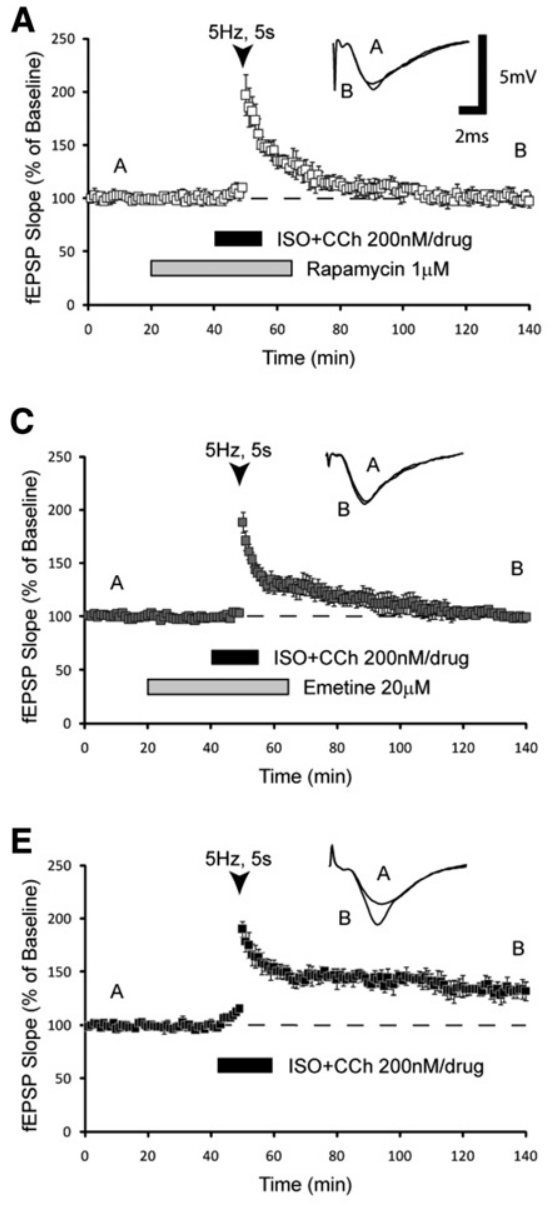

B
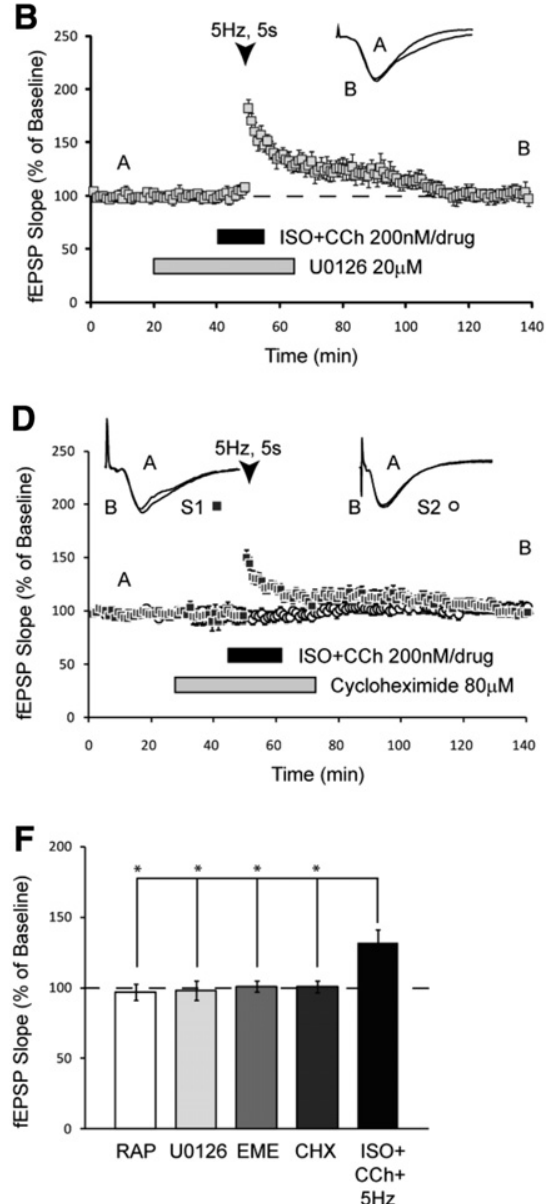

Figure 3. Coapplication of ISO and CCh engages protein synthesis to bolster LTP. (A) Application of the mTOR inhibitor rapamycin overlapping with ISO and CCh prevented the induction of LTP $(n=6)$. (B) Slices treated with U0126 (MEK inhibitor) similarly exhibited decremental LTP $(n=8)$. (C) Repression of translation using emetine $(n=8)$ resulted in LTP which was significantly reduced relative to inhibitor-free controls $(E, F ; n=8)$, when compared 90 min post-stimulation. $(D)$ To control for nonspecific effects of EME, we used a second translation repressor, cycloheximide. Similar to EME, CHX (dark gray squares) blocked the maintenance of LTP. A second pathway (S2; open circles) was monitored to confirm slice health. (F) Summary histogram comparing fEPSP slopes obtained 90 min after LFS. Sample traces were taken $10 \mathrm{~min}$ after commencement of baseline recordings and $90 \mathrm{~min}$ after HFS. Results in $F$ represent means \pm SEM. $\left({ }^{*}\right) P<0.05$.

(Scheiderer et al. 2008). Here, we have confirmed the initial results of Watabe et al. (2000) and extended the characterization of mechanisms by which $\beta$ - and muscarinic receptors synergistically modulate long-lasting synaptic plasticity.

Our data suggest that, when paired together, submicromolar concentrations of isoproterenol and carbachol initiate intracellular signaling cascades capable of extending the duration of synaptic potentiation induced by a low-frequency stimulation protocol $(5 \mathrm{~Hz})$ which normally produces relatively transient $(<45 \mathrm{~min}$ ) STP. We have shown that the effects of ISO are mediated through $\beta 1$ - but not $\beta 2$-adrenergic receptors, as the facilitative effects of ISO + CCh were blocked by CGP ( $\beta 1$ antagonist) but were preserved in the presence of ICI ( $\beta 2$ antagonist). Recent data suggest that prolonged $\theta$-frequency stimulation paired with ISO application induces LTP requiring $\beta 2$-ARs but not $\beta 1$ (Qian et al. 2012). However, prior evidence generated using $\beta 1$-AR KO mice found deficits in $\Theta+$ ISO LTP that was not observed in $\beta 2$ KOs (Winder et al. 1999). An important difference between these protocols is the duration of stimulation ( $3 \mathrm{~min}$ and $5 \mathrm{sec}$, respectively) which may lead to a preferential engagement of one $\beta$-adrenergic receptor subtype over another. Indeed, prolonged $\theta$ stimulation in the presence of ISO increases the number of complex spikes which did not require the activation of PKA (Gelinas et al. 2008). As the more modest protocol used in our present study elicited LTP that was disrupted following inhibition of PKA, taken together, these results suggest divergence of receptor and downstream signaling that is dependent upon the duration of $\theta$ stimulation.

The relatively low concentrations of ISO or the presence of a second neuromodulatory agonist may also explain the favored initiation of signal mechanisms downstream of $\beta 1$-ARs, whereas the Qian et al. (2012) data were based on the presence of ISO alone which may necessitate the engagement of both receptor subtypes. Future research combining receptor subtype-specific agonists will be required to further delineate the putative interactions of these neuromodulatory signaling mechanisms. Evidence suggests that the $\beta 1$-AR couples to Gos which elicits cAMP generation and activates downstream signaling kinases including PKA and ERK (Winder et al. 1999; Vanhoose and Winder 2003). Isoproterenol can activate $\beta 1$-ARs (Fowler and O'Donnell 1988) which have been specifically implicated in $\theta$-frequency LTP protocols (Winder et al. 1999).

We have also further clarified the muscarinic receptor component which appears to require $\mathrm{M} 1$, but not $\mathrm{M} 2 / \mathrm{M} 4$ or $\mathrm{M} 3 / \mathrm{M} 5$, muscarinic receptors. Application of pirenzepine inhibited LTP, whereas methoctramine or 4-DAMP failed to block the enhancement of LTP observed in the presence of ISO and CCh. Similar to $\beta$-adrenergic receptors (Gelinas et al. 2007), M1 muscarinic receptors are capable of inducing ERK activation (Berkeley et al. 2001) which has been linked to translation-dependent long-term depression in rat visual cortex (McCoy and McMahon 2007).

What cellular mechanisms are initiated by coactivation of $\beta$ and muscarinic receptors to convert STP to translation-dependent LTP? These results suggest that coactivation of $\beta$ - and muscarinic receptors engages PKA to increase the duration of LTP, which is associated with AMPAR trafficking and membrane insertion, highly dynamic processes subject to regulation through phosphorylation (Makino and Malinow 2009; Makino et al. 2011). Activation of $\beta$-adrenergic receptors increases membrane insertion of GluR1 through PKA-dependent phosphorylation (Esteban et al. 2003; Hu et al. 2007; Tenorio et al. 2010). Similarly, GluR1 insertion is up-regulated following in vitro treatment with $\mathrm{ACh}$, an effect mediated through M1-dependent signaling (Fernández de Sevilla et al. 2008). Although not determined in the Fernández de Sevilla study, activation of PKC downstream of muscarinic receptors can increase phosphorylation of Serine-831 on GluR1, a key event implicated in AMPAR trafficking and insertion (Boehm et al. 2006). Future research is needed to determine the role of 
AMPA receptor trafficking in LTP induced through coactivation of $\beta$ - and muscarinic receptors.

Inhibition of mTOR prevented the maintenance of LTP induced by ISO paired with CCh. Although evidence implicating muscarinic receptors in mTOR regulation is sparse, one report has implicated the M3 muscarinic receptor in mTOR regulation (Slack and Blusztajn 2008). As our results have implicated the M1 muscarinic receptor but not M3, this suggests that the $\beta 1$-AR may be primarily responsible for mTOR regulation (Gelinas et al. 2007).

Previous research has implicated ERK in both long-term memory formation and synaptic plasticity (Atkins et al. 1998; Banko et al. 2006; Gelinas et al. 2007). Initiation of translation is enhanced following ERK activation, which is linked to long-lasting plasticity (Kelleher et al. 2004; Gelinas et al. 2007). Both $\beta 1$-ARs (Roberson et al. 1999) and muscarinic receptors (Berkeley et al. 2001) are capable of ERK activation. Additionally, both muscarinic and $\beta$-adrenergic receptors can engage PKC and PKA signaling, respectively, to increase phosphorylation of ERK (Roberson et al. 1999; Gelinas et al. 2008). Consistent with previous data (Watabe et al. 2000), application of the MEK inhibitor, U0126, prevented the maintenance of LTP induced by coactivation of $\beta$ - and muscarinic receptors. Taken together, our results suggest that costimulation of $\beta$-adrenergic and muscarinic receptors induces LTP, which requires $\mathrm{mTOR}$ and ERK activation. As both mTOR and ERK are capable of effecting translation regulation which has been implicated in long-lasting forms of synaptic plasticity (Banko et al. 2006; Gelinas et al. 2007), our results provide evidence for a potential dual neuromodulatory receptor-initiated mechanism for augmenting long-term synaptic plasticity.

The synthesis of proteins has been implicated in many forms of synaptic plasticity and memory formation (for review, see Klann et al. 2004; Richter and Sonenberg 2005; Costa-Mattioli et al. 2009). Persistent LTP requires translation (Stanton and Sarvey 1984; Frey et al. 1988; Kandel 2001; Scharf et al. 2002; Gelinas and Nguyen 2005). As both ERK and mTOR are capable of regulating translation through interactions with Mnk1 and 4E-binding proteins, respectively (Gelinas et al. 2007; Costa-Mattioli et al. 2009), our results suggest that translation regulation is a mechanism by which coapplication of ISO and CCh enhances the transformation of STP to LTP. Consistent with this postulate, inhibition of translation with emetine or cycloheximide prevented the maintenance of LTP induced by simultaneous activation of $\beta$ and muscarinic receptors. It should be noted that the observed effects of inhibition of protein synthesis appeared to be relatively rapid. The main reasons for this observation are twofold. First, using a mild stimulation protocol $(5 \mathrm{~Hz}, 5 \mathrm{sec})$ may yield LTP that does not engage secondary cellular events (calcium influx, kinase activation) to the same extent as that of multitrain, high-frequency stimulation protocols. As such, the translation-independent component of LTP engaged by stronger LTP protocols may mask an early, translation-dependent component. Secondly, the translation-dependent processes initiated by this protocol may differ in the component of LTP affected (induction or maintenance) or the time course of the translational processes. Indeed, previous research suggests that mTOR-dependent translation of GluR1 is required within $15 \mathrm{~min}$ of inhibitory avoidance training for longterm memory formation (Slipczuk et al. 2009) which is within the timeframes reported here. The effects of coactivating $\beta$ - and muscarinic receptors on memory formation in vivo have yet to be determined.

Understanding how distinct neuromodulatory receptors interact to regulate synaptic plasticity should provide novel insights into memory consolidation. As disruption of both cholinergic and noradrenergic neuromodulatory systems can impair synaptic plasticity and has been implicated in the pathology of neurodegenerative disorders that perturb memory consolidation
(Caccamo et al. 2006; Yu et al. 2011), defining how neuromodulatory systems interact is critical for generating precise therapies for the treatment of neurodegenerative disorders.

\section{Materials and Methods}

\section{Animals}

Male C57BL/6 mice were used for all experiments. Animals were housed at the University of Alberta according to guidelines of Canadian Council on Animal Care (CCAC). All mice were maintained on a 12-h on/off light cycle in social housing, with food and water available ad libitum. Approximately 197 C57BL/6 mice (aged 7-14 wk) were used for these experiments.

\section{Electrophysiology}

Following cervical dislocation and decapitation, the brain was removed and placed in ice-cold artificial cerebrospinal fluid (ACSF). Each hippocampus was dissected out of the remaining tissue and sliced in the transverse plane (400- $\mu \mathrm{m}$ thickness) (as described in Nguyen and Kandel 1997). Slices were then transferred to an interface chamber and maintained at $28^{\circ} \mathrm{C}$ (Gelinas and Nguyen 2005; Gelinas et al. 2007). ACSF was composed of (in mM) $124 \mathrm{NaCl}, 4.4$ $\mathrm{KCl}, 1.3 \mathrm{MgSO}_{4}, 1.0 \mathrm{NaH}_{2} \mathrm{PO}_{4}, 26.2 \mathrm{NaHCO}_{3}, 2.5 \mathrm{CaCl}_{2}$, and 10 glucose, aerated with $95 \% \mathrm{O}_{2}$ and $5 \% \mathrm{CO}_{2}$, and was applied at a flow rate of $1.5 \mathrm{~mL} / \mathrm{min}$. Extracellular field excitatory postsynaptic potentials (fEPSPs) were recorded with a glass microelectrode filled with ACSF (resistances, 2-3 M 2 ). Both the recording electrode and a bipolar nickel-chromium stimulating electrode were positioned in the stratum radiatum of area CA1. fEPSPs were elicited by stimulating Schaffer collateral (SC) fibers projecting onto CA1 apical dendrites. Maximal evoked fEPSPs were generated by increasing the stimulation intensity until no further increase in fEPSP amplitude could be obtained. Subsequent test pulses (1/ min; 0.08-ms pulse duration) were adjusted to elicit a fEPSP that was $40 \%$ of the maximum evoked value (Woo and Nguyen 2003; Gelinas and Nguyen 2005). fEPSPs elicited at this level constituted our baseline responses.

$\beta$-AR- and muscarinic receptor-dependent LTP was induced by applying one train of low-frequency stimulation $(5 \mathrm{~Hz}, 5 \mathrm{sec})$ following a 10-min coapplication of a $\beta$-AR agonist, isoproterenol (ISO; $200 \mathrm{nM}$ ), and a muscarinic agonist, carbachol (CCh; $200 \mathrm{nM}$ ) (Watabe et al. 2000). Following LFS, ISO and CCh were applied for an additional 5 min.

\section{Drugs}

The $\beta$-AR agonist, $\mathrm{R}(-)$-isoproterenol(+)-bitartrate (ISO, Sigma) and the muscarinic receptor agonist carbachol (CCh; Sigma) were prepared daily in distilled water as concentrated stock solutions at $1 \mathrm{mM}$, and coapplied at a final concentration of $200 \mathrm{nM}$ each. The $\beta$-AR antagonist ( \pm )-propranolol hydrochloride (PROP; $50 \mu \mathrm{M}$; Sigma) was also prepared daily in distilled water as a $50 \mathrm{mM}$ stock solution. Both the specific $\beta 1$-AR antagonist, ( \pm )-2-Hydroxy-5-[2-[[2-hydroxy-3-[4-[1-methyl-4-(trifluoromethyl)-1H-imidazol-2-yl]phenoxy]propyl] amino]ethoxy]-benzamide methanesulfonate salt (CGP-20712A; CGP; Sigma) and 32-AR antagonist, $( \pm$ )-1-[2,3-(Dihydro-7-methyl-1H-inden-4-yl) oxy]-3-[(1-methylethyl)amino]-2-butanol hydrochloride (ICI 118,551; ICI; Sigma) were prepared at stock concentrations of $1 \mathrm{mM}$ and diluted to a final concentration of $1 \mu \mathrm{M}$. The muscarinic receptor antagonist, atropine (Sigma) was dissolved in ethanol at $50-\mathrm{mM}$ stock concentration and diluted to $50 \mu \mathrm{M}$ prior to application. An M1 muscarinic receptor antagonist, pirenzepine dihydrochloride (PIR; Sigma), was dissolved in distilled water (1-mM stock) and applied at $250 \mathrm{nM}$. The M3/M5 muscarinic receptor antagonist, 4-diphenylacetoxy-N-methylpiperidine methiodide (4-DAMP; $1 \mu \mathrm{M}$; Sigma), was dissolved in dimethylsulfoxide (DMSO), yielding a stock concentration of $1 \mathrm{mM}$. Methoctramine, an M2/M4 antagonist, was prepared in distilled water at $1-\mathrm{mM}$ stock concentration and diluted to $1 \mu \mathrm{M}$. 
To assay for a requirement of activation of cAMP-dependent protein kinase, we applied a protein kinase A inhibitor, PKI (PKA Inhibitor 14-22 Amide, cell-permeable, myristoylated; $1 \mu \mathrm{M}$; Calbiochem), dissolved in distilled water. PKI was applied $20 \mathrm{~min}$ prior to and overlapping with ISO + CCh. The MEK inhibitor, 1,4-diamino-2,3-dicyano-1,4-bis[2-aminophenylthio] butadiene (U0126; $20 \mu \mathrm{M}$; Sigma), was prepared in DMSO at a concentration of $20 \mathrm{mM}$. An mTOR inhibitor, rapamycin (RAP; $1 \mu \mathrm{M}$; Sigma), was dissolved in DMSO to make stock solutions at $1 \mathrm{mM}$. U0126 and RAP were perfused for 20 min prior to commencing experiments, overlapping with ISO application, and $10 \mathrm{~min}$ following ISO. A translation inhibitor, emetine (EME; Sigma), was dissolved to a stock concentration of $20 \mathrm{mM}$ in distilled water and perfused at $20 \mu \mathrm{M}, 20 \mathrm{~min}$ prior to ISO application. At lower concentrations than $20 \mu \mathrm{M}$, EME was shown to block protein synthesis by $>80 \%$ in hippocampal slices (Stanton and Sarvey 1984). A second protein synthesis inhibitor, cycloheximide $(80 \mu \mathrm{M})$, was used to control for off-target effects of emetine. All drug experiments were performed under dimmed light conditions due to photosensitivity of the drugs. Drug experiments were interleaved with drug-free controls.

\section{Data analysis}

The initial slope of the fEPSP was measured as an index of synaptic strength (Johnston and Wu 1995). The average "baseline" slope values were acquired for $20 \mathrm{~min}$ before experimental protocols were applied. fEPSP slopes were measured at either 60 or $90 \mathrm{~min}$ after LFS for comparisons of LTP. Student's t test was used for statistical comparisons of mean fEPSP slopes between two groups, with a significance level of $P<0.05$ (denoted with an asterisk [*] on graphs). One-way ANOVA and Tukey-Kramer post-hoc tests were done for comparison of more than two groups to determine which groups were significantly different from the others. The Welch correction was applied in cases in which the SDs of compared groups were significantly different. All values shown are means $\pm S E M$, with $n=$ number of slices.

\section{Acknowledgments}

This research was funded by the Canadian Institutes of Health Research and the Natural Sciences and Engineering Research Council of Canada. S.A.C. received a Graduate Scholarship from the Natural Sciences and Engineering Research Council of Canada, and P.V.N. is a scientist of the Alberta Heritage Foundation for Medical Research. We thank Gustavo Tenorio for his technical assistance.

\section{References}

Abel T, Nguyen PV, Barad M, Deuel TA, Kandel ER, Bourtchouladze R. 1997. Genetic demonstration of a role for PKA in the late phase of LTP and in hippocampus-based long-term memory. Cell 88: 615-626.

Abraham WC, Williams JM. 2008. LTP maintenance and its protein synthesis-dependence. Neurobiol Learn Mem 89: 260-268.

Atkins CM, Selcher JC, Petraitis JJ, Trzaskos JM, Sweatt JD. 1998. The MAPK cascade is required for mammalian associative learning. Nat Neurosci 1: 602-609.

Banko JL, Hou L, Poulin F, Sonenberg N, Klann E. 2006. Regulation of eukaryotic initiation factor $4 \mathrm{E}$ by converging signaling pathways during metabotropic glutamate receptor-dependent long-term depression. J Neurosci 26: 2167-2173.

Berkeley JL, Gomeza J, Wess J, Hamilton SE, Nathanson NM, Levey AI. 2001. M1 muscarinic acetylcholine receptors activate extracellular signal-regulated kinase in CA1 pyramidal neurons in mouse hippocampal slices. Mol Cell Neurosci 18: 512-524.

Bliss TVP, Collingridge GL. 1993. A synaptic model of memory: Long-term potentiation in the hippocampus. Nature 361: 31-39.

Bliss TV, Lomo T. 1973. Long-lasting potentiation of synaptic transmission in the dentate area of the anaesthetized rabbit following stimulation of the perforant path. J Physiol 232: 331-356.

Boehm J, Kang MG, Johnson RC, Esteban J, Huganir RL, Malinow R. 2006. Synaptic incorporation of AMPA receptors during LTP is controlled by a PKC phosphorylation site on GluR1. Neuron 51: $213-225$.
Caccamo A, Oddo S, Billings LM, Green KN, Martinez-Coria H, Fisher A, LaFerla FM. 2006. M1 receptors play a central role in modulating AD-like pathology in transgenic mice. Neuron 49: 671-682.

Cahill L, Prins B, Weber M, McGaugh JL. 1994. $\beta$-adrenergic activation and memory for emotional events. Nature 371: 702-704.

Costa-Mattioli M, Sossin WS, Klann E, Sonenberg N. 2009. Translational control of long-lasting synaptic plasticity and memory. Neuron 61: $10-26$.

Dringenberg HC, Oliveira D, Habib D. 2008. Predator (cat hair)-induced enhancement of hippocampal long-term potentiation in rats: Involvement of acetylcholine. Learn Mem 15: 112-116.

Esteban JA, Shi SH, Wilson C, Nuriya M, Huganir RL, Malinow R. 2003. PKA phosphorylation of AMPA receptor subunits controls synaptic trafficking underlying plasticity. Nat Neurosci 6: $136-143$.

Feig S, Lipton P. 1993. Pairing the cholinergic agonist carbachol with patterned Schaffer collateral stimulation initiates protein synthesis in hippocampal CA1 pyramidal cell dendrites via a muscarinic, NMDA-dependent mechanism. J Neurosci 13: 1010-1021.

Fernández de Sevilla D, Buño W. 2010. The muscarinic long-term enhancement of NMDA and AMPA receptor-mediated transmission at Schaffer collateral synapses develop through different intracellular mechanisms. J Neurosci 30: 11032-11042.

Fernández de Sevilla D, Núñez A, Borde M, Malinow R, Buño W. 2008. Cholinergic-mediated IP3-receptor activation induces long-lasting synaptic enhancement in CA1 pyramidal neurons. J Neurosci 28: $1469-1478$.

Fowler JC, O'Donnell JM. 1988. Antagonism of the responses to isoproterenol in the rat hippocampal slice with subtype-selective antagonists. Eur J Pharmacol 153: 105-110.

Frey U, Krug M, Reymann KG, Matthies H. 1988. Anisomycin, an inhibitor of protein synthesis, blocks late phases of LTP phenomena in the hippocampal CA1 region in vitro. Brain Res 452: 57-65.

Frey U, Matthies H, Reymann KG, Matthies H. 1991. The effect of dopaminergic D1 receptor blockade during tetanization on the expression of long-term potentiation in the rat CA1 region in vitro. Neurosci Lett 129: 111-114.

Gelinas JN, Nguyen PV. 2005. $\beta$-adrenergic receptor activation facilitates induction of a protein synthesis-dependent late phase of long-term potentiation. J Neurosci 25: 3294-3303.

Gelinas JN, Banko JL, Hou L, Sonenberg N, Weeber EJ, Klann E, Nguyen PV. 2007. ERK and mTOR signaling couple $\beta$-adrenergic receptors to translation initiation machinery to gate induction of protein synthesis-dependent long-term potentiation. J Biol Chem 282: 27527-27535.

Gelinas JN, Tenorio G, Lemon N, Abel T, Nguyen PV. 2008. $\beta$-adrenergic receptor activation during distinct patterns of stimulation critically modulates the PKA-dependence of LTP in the mouse hippocampus. Learn Mem 15: 281-289.

Harley CW, Darby-King A, McCann J, McLean JH. 2006. $\beta 1$-adrenoceptor or $\beta 1$-adrenoceptor activation initiates early odor preference learning in rat pups: Support for the mitral cell/cAMP model of odor preference learning. Learn Mem 13: 8-13.

Herrera-Morales W, Mar I, Serrano B, Bermúdez-Rattoni F. 2007. Activation of hippocampal postsynaptic muscarinic receptors is involved in long-term spatial memory formation. Eur J Neurosci 25: $1581-1588$.

Hu H, Real E, Takamiya K, Kang MG, Ledoux J, Huganir RL, Malinow R. 2007. Emotion enhances learning via norepinephrine regulation of AMPA-receptor trafficking. Cell 131: 160-173.

Johnston D, Wu SM-S. 1995. Foundations of cellular neurophysiology. MIT Press, Cambridge, MA.

Kandel ER. 2001. The molecular biology of memory storage: A dialogue between genes and synapses. Science 294: 1030-1038.

Kelleher RJ III, Govindarajan A, Jung HY, Kang H, Tonegawa S. 2004. Translational control by MAPK signaling in long-term synaptic plasticity and memory. Cell 116: $467-479$.

Kemp A, Manahan-Vaughan D. 2008. $\beta$-adrenoreceptors comprise a critical element in learning-facilitated long-term plasticity. Cereb Cortex 18: 1326-1334.

Klann E, Antion MD, Banko JL, Hou L. 2004. Synaptic plasticity and translation initiation. Learn Mem 11: 365-372.

Kukolja J, Thiel CM, Fink GR. 2009. Cholinergic stimulation enhances neural activity associated with encoding but reduces neural activity associated with retrieval in humans. J Neurosci 29: 8119-8128.

Lemon N, Aydin-Abidin S, Funke KU, Manahan-Vaughan D. 2009. Locus coeruleus activation facilitates memory encoding and induces hippocampal LTD that depends on $\beta$-adrenergic receptor activation. Cereb Cortex 19: 2827-2837.

Leung LS, Shen B, Rajakumar N, Ma J. 2003. Cholinergic activity enhances hippocampal long-term potentiation in CA1 during walking in rats. $J$ Neurosci 23: 9297-9304. 
Li S, Cullen WK, Anwyl R, Rowan MJ. 2007. Muscarinic acetylcholine receptor-dependent induction of persistent synaptic enhancement in rat hippocampus in vivo. Neuroscience 144: 754-761.

Makino H, Malinow R. 2009. AMPA receptor incorporation into synapses during LTP: The role of lateral movement and exocytosis. Neuron 64: 381-390.

Makino Y, Johnson RC, Yu Y, Takamiya K, Huganir RL. 2011. Enhanced synaptic plasticity in mice with phosphomimetic mutation of the GluA1 AMPA receptor. Proc Natl Acad Sci 108: 8450-8455.

McCoy PA, McMahon LL. 2007. Muscarinic receptor dependent long-term depression in rat visual cortex is PKC independent but requires ERK1/2 activation and protein synthesis. J Neurophysiol 98: 1862-1870.

Neves G, Cooke SF, Bliss TVP. 2008. Synaptic plasticity, memory, and the hippocampus: A neural network approach to causality. Nat Rev Neurosci 9: $65-75$.

Nguyen PV, Kandel ER. 1997. Brief $\theta$-burst stimulation induces a transcription-dependent late phase of LTP requiring cAMP in area CA1 of the mouse hippocampus. Learn Mem 4: 230-243.

Nguyen PV, Abel T, Kandel ER. 1994. Requirement of a critical period of transcription for induction of a late phase of LTP. Science 265: 1104-1107.

Poulin B, Butcher A, McWilliams P, Bourgognon JM, Pawlak R, Kong KC, Bottrill A, Mistry S, Wess J, Rosethorne EM, et al. 2010. The M3muscarinic receptor regulates learning and memory in a receptor phosphorylation/arrestin-dependent manner. Proc Natl Acad Sci 107: 9440-9445.

Qian H, Matt L, Zhang M, Nguyen M, Patriarchi T, Koval OM, Anderson ME, He K, Lee HK, Hell JW. 2012. $\beta 2$-Adrenergic receptor supports prolonged $\theta$ tetanus-induced LTP. J Neurophysiol 107: 2703-2712.

Richter JD, Sonenberg N. 2005. Regulation of cap-dependent translation by eIF4E inhibitory proteins. Nature 433: 477-480.

Roberson ED, English JD, Adams JP, Selcher JC, Kondratick C, Sweatt JD. 1999. The mitogen-activated protein kinase cascade couples PKA and PKC to cAMP response element binding protein phosphorylation in area CA1 of hippocampus. J Neurosci 19: 4337-4348.

Scharf MT, Woo NH, Lattal KM, Young JZ, Nguyen PV, Abel T. 2002. Protein synthesis is required for the enhancement of long-term potentiation and long-term memory by spaced training. J Neurophysiol 87: $2770-2777$.

Scheiderer CL, Smith CC, McCutchen E, McCoy PA, Thacker EE, Kolasa K, Dobrunz LE, McMahon LL. 2008. Coactivation of M(1) muscarinic and $\theta 1$ adrenergic receptors stimulates extracellular signal-regulated protein kinase and induces long-term depression at CA3-CA1 synapses in rat hippocampus. J Neurosci 28: 5350-5358.

Scoville WB, Milner B. 1957. Loss of recent memory after bilateral hippocampal lesions. J Neurol Neurosurg Psychiatry 20: 11-21.

Shinoe T, Matsui M, Taketo MM, Manabe T. 2005. Modulation of synaptic plasticity by physiological activation of M1 muscarinic acetylcholine receptors in the mouse hippocampus. J Neurosci 25: 11194-11200.

Slack BE, Blusztajn JK. 2008. Differential regulation of mTOR-dependent S6 phosphorylation by muscarinic acetylcholine receptor subtypes. J Cell Biochem 104: 1818-1831.
Slipczuk L, Bekinschtein P, Katche C, Cammarota M, Izquierdo I, Medina JH. 2009. BDNF activates mTOR to regulate GluR1 expression required for memory formation. PLoS One 4: e6007. doi: 10.1371/ journal.pone.0006007.

Stanton PK, Sarvey JM. 1984. Blockade of long-term potentiation in rat hippocampal CA1 region by inhibitors of protein synthesis. J Neurosci 4: $3080-3088$.

Straube T, Korz V, Balschun D, Frey JU. 2003. Requirement of $\beta$-adrenergic receptor activation and protein synthesis for LTP-reinforcement by novelty in rat dentate gyrus. J Physiol 552: 953-960.

Tenorio G, Connor SA, Guévremont D, Abraham WC, Williams J, O'Dell TJ, Nguyen PV. 2010. 'Silent' priming of translation-dependent LTP by $B$-adrenergic receptors involves phosphorylation and recruitment of AMPA receptors. Learn Mem 17: 627-638.

Thomas MJ, Moody TD, Makhinson M, O'Dell TJ. 1996. Activity-dependent $\beta$-adrenergic modulation of low frequency stimulation induced LTP in the hippocampal CA1 region. Neuron 17: $475-482$.

Vanhoose AM, Winder DG. 2003. NMDA and $\beta 1$-adrenergic receptors differentially signal phosphorylation of glutamate receptor type 1 in area CA1 of hippocampus. J Neurosci 23: 5827-5834.

Wallenstein GV, Vago DR. 2001. Intrahippocampal scopolamine impairs both acquisition and consolidation of contextual fear conditioning. Neurobiol Learn Mem 75: 245-252.

Walling SG, Harley CW. 2004. Locus ceruleus activation initiates delayed synaptic potentiation of perforant path input to the dentate gyrus in awake rats: A novel $\beta$-adrenergic- and protein synthesis-dependent mammalian plasticity mechanism. J Neurosci 24: 598-604.

Watabe AM, Zaki PA, O'Dell TJ. 2000. Coactivation of $\beta$-adrenergic and cholinergic receptors enhances the induction of long-term potentiation and synergistically activates mitogen-activated protein kinase in the hippocampal CA1 region. J Neurosci 20: 5924-5931.

Whitlock JR, Heynen AJ, Shuler MG, Bear MF. 2006. Learning induces long-term potentiation in the hippocampus. Science 313: 1093-1097.

Winder DG, Martin KC, Muzzio IA, Rohrer D, Chruscinski A, Kobilka B, Kandel ER. 1999. ERK plays a regulatory role in induction of LTP by $\theta$ frequency stimulation and its modulation by $\beta$-adrenergic receptors. Neuron 24: $715-726$.

Woo NH, Nguyen PV. 2003. Protein synthesis is required for synaptic immunity to depotentiation. J Neurosci 23: $1125-1132$.

Yu JT, Wang ND, Ma T, Jiang H, Guan J, Tan L. 2011. Roles of $\beta$-adrenergic receptors in Alzheimer's disease: Implications for novel therapeutics. Brain Res Bull 84: 111-117.

Zola-Morgan S, Squire LR, Amaral DG. 1986. Human amnesia and the medial temporal region: Enduring memory impairment following a bilateral lesion limited to field CA1 of the hippocampus. J Neurosci 6: 2950-2967.

Received May 5, 2012; accepted in revised form August 2, 2012. 


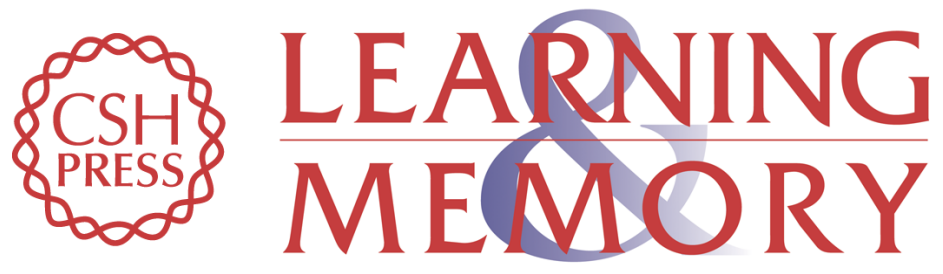

Conversion of short-term potentiation to long-term potentiation in mouse CA1 by coactivation of $\beta$-adrenergic and muscarinic receptors

Steven A. Connor, Sabyasachi Maity, Birbickram Roy, et al.

Learn. Mem. 2012, 19:

Access the most recent version at doi:10.1101/lm.026898.112

References This article cites 62 articles, 29 of which can be accessed free at: http://learnmem.cshlp.org/content/19/11/535.full.html\#ref-list-1

License

Email Alerting

Receive free email alerts when new articles cite this article - sign up in the box at the Service top right corner of the article or click here. 